\title{
Femtosecond laser assisted cataract surgery in a cataract patient with a " 0 vaulted" ICL: a case report
}

\author{
Yibo Yu, Chengshou Zhang and Yanan Zhu*
}

\begin{abstract}
Background: Femtosecond laser assisted cataract surgery (FLACS) combined with implantable collamer lenses (ICLs) extraction has been shown to be a feasible method for patients developing cataracts after the ICL implantation. All reported cases had shallow vaults, ranging from $47 \mu \mathrm{m}(\mu \mathrm{m})$ to $100 \mu \mathrm{m}$. We report for the first time, a case in which the FLACS was performed on the " 0 " vault eye.
\end{abstract}

Case presentation: A 38-year-old man with anterior subcapsular cataracts underwent the FLACS combined with ICLs extraction 6 years after ICLs implantation in both eyes. In his left eye, the ICL touched the anterior capsule, existing "O" vault. During the capsulotomy, cavitation bubbles were trapped in the shallow space beneath the ICL, developing from small bubbles into big ones, which resulted in the incomplete capsulotomy. Comparatively, in the right eye, the ICL vault was measured $72 \mu \mathrm{m}$, and the capsulotomy was complete and no big cavitation bubbles formed. In both eyes, capsulotomy zones were manually assigned to the anterior capsule surface in the process of laser identification. However, the nuclear pre-fragmentations were unsuccessful in both eyes. Other steps of surgeries were performed uneventfully. Depending on the design of monovision, the uncorrected distance visual acuity (UDVA) was 20/32, and the near uncorrected visual acuity (UCVA) was 20/25 in both eyes postoperatively.

Conclusions: This case suggested that the surgeon should pay attention to the incomplete laser capsulotomy when using a femtosecond laser in cataractous cases with "O" vaulted ICLs, and manual adjustment was required in the process of laser identification.

Keywords: Femtosecond laser, Cataract surgery, ICL, 0 vault, Case report

\section{Background}

The use of femtosecond lasers in cataract surgery has become commonplace, expanding from common cases to complicated cases [1-3]. Special cases have been reported in which the femtosecond laser has been used in cataract patients who have implantable collamer lenses (ICLs) in situ [4, 5]. Combined ICL extraction and femtosecond laser assisted cataract surgery (FLACS) with posterior chamber implantable ocular lens (IOL)

\footnotetext{
* Correspondence: 2313070@zju.edu.cn

Eye Center of the 2nd Affiliated Hospital, School of Medicine, Zhejiang University, No.88 Jiefang Road, Hangzhou, China
}

implantation has been shown to be a feasible method in these special cases. All reported cases had shallow vaults, ranging from $47 \mu \mathrm{m}(\mu \mathrm{m})$ to $100 \mu \mathrm{m}[4,5]$.

Here, we discuss a special patient with ICLs who developed cataracts in both eyes, and one of the eyes had a "0" vault. We compare the process of using FLACS between the " 0 " vault and the shallow vault in one patient and describe the difference in the FLACS in the "0" vault eye.

\section{Case presentation}

A 38-year-old man presented with decreased vision in both eyes for 2 years. The patient had undergone ICL

(c) The Author(s). 2020 Open Access This article is licensed under a Creative Commons Attribution 4.0 International License, which permits use, sharing, adaptation, distribution and reproduction in any medium or format, as long as you give appropriate credit to the original author(s) and the source, provide a link to the Creative Commons licence, and indicate if changes were made. The images or other third party material in this article are included in the article's Creative Commons licence, unless indicated otherwise in a credit line to the material. If material is not included in the article's Creative Commons licence and your intended use is not permitted by statutory regulation or exceeds the permitted use, you will need to obtain permission directly from the copyright holder. To view a copy of this licence, visit http://creativecommons.org/licenses/by/4.0/. The Creative Commons Public Domain Dedication waiver (http://creativecommons.org/publicdomain/zero/1.0/) applies to the data made available in this article, unless otherwise stated in a credit line to the data. 
(ICL V4 Visian, STAAR Surgical Co., Monrovia, California, U.S.A.) implantation in both eyes 6 years prior. Postoperatively, the uncorrected distance visual acuity (UDVA) of both eyes was 20/32. The corrected distance visual acuity (CDVA) was similar to the UDVA.

On examination, ICLs were in situ with anterior subcapsular cataracts in both eyes (Fig. 1). Both eyes underwent anterior segment optical coherence tomography (AS-OCT; CASIA SS-1000, Tomey Corp., Nagoya, Japan) imagining in the model of 3D. Then the ICL vault was manually measured from the back surface of the ICL to the front surface of crystalline lens, centered on the optic axis (shown as a white beam). The vault was shallow in the right eye and measured $72 \mu \mathrm{m}$ through AS-OCT images. However, in the left eye, the ICL touched the anterior capsule, existing " 0 " vault (Fig. 1). The endothelial cell density, calculated by the noncontact autofocus specular microscope (EM-3000, Tomey Corp., Nagoya, Japan), was 2587 cells/millimeter squared $\left(\mathrm{mm}^{2}\right)$ in the right eye and 2531 cells/mm in the left eye.

The patient had planned explantation of the ICL with FLACS after obtaining written informed consent. Considering the unsatisfactory CDVA of the patient after ICL implantation, the surgeon suggested a monovision design for the patient with the implantation of monofocal IOLs rather than multifocal IOLs. And the LenSx laser system (LenSx Laser, Alcon Laboratories, Inc., Fort Worth, Texas, U.S.A.) was used for capsulotomy (5.1 $\mathrm{mm}$ diameter, $8 \mu \mathrm{J}$ energy) and chop nuclear prefragmentation ( $5.0 \mathrm{~mm}$ diameter, 6 chops, $8 \mu \mathrm{J}$ energy).

The surgery was performed first in the left " 0 " vault eye. Cavitation bubbles were trapped in the shallow space beneath the ICL around the capsulotomy area during the capsulotomy, developing from small bubbles into big ones (Fig. 2). No additional cavitation bubbles appeared during nuclear pre-fragmentation.

Then, a $2.0 \mathrm{~mm}$ primary superior corneal incision was made with a keratome at 135 degrees $\left({ }^{\circ}\right)$. The sodium hyaluronate $1.7 \%$ ophthalmic viscosurgical device (OVD, Amvisc Plus, Bausch \& Lomb, Inc.) was injected into the anterior chamber. At first, we attempted to remove the ICL directly without rotating it but failed with the rupture of the ICL. Next, we carefully rotated the ICL. After its vertical angle faced the incision, the ICL was grasped with forceps and extracted through the corneal incision. After the removal of the ICL, the capsulotomy was found to be incomplete between the coordinates of nine o'clock and two o'clock. A second capsulorhexis according to the laser tracks was safely made (Fig. 3). The nuclear pre-fragmentation was unsuccessful and could not be tracked.

The phacoemulsification was manipulated in a standard stop-and-chop manner with the Stellaris system (Bausch \& Lomb Laboratories, Rochester, New York, U.S.A.), followed by the implantation of the hydrophobic IOL (Tecnis ZCB00, Abbott Medical Optics Inc., Santa Ana, CA) in the capsular bag.

The surgery was performed on the right eye one and a half months later. Learning from the experience of the left eye surgery, we made a $3.0 \mathrm{~mm}$ temporal corneal incision in the right eye, and the ICL was extracted smoothly without rotation. This time, the capsulotomy was complete. Lots of small cavitation bubbles appeared, dispersing to the central area, and no big bubbles
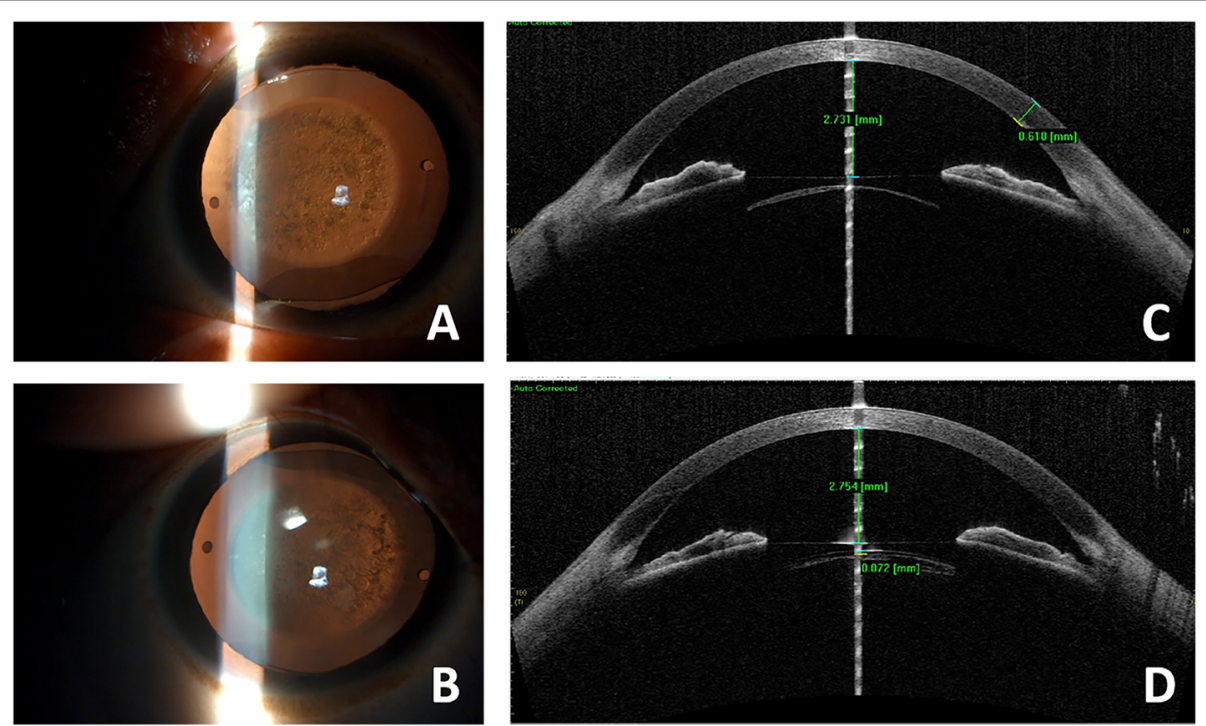

Fig. 1 The slit lamp photographs and AS-OCT images of both eyes (a to $\mathbf{d}$ ). a-b The slit lamp photographs showed the lenses' anterior subcapsular opacities and ICL in situ. c-d The AS-OCT images of both eyes showed the ICL was touching the anterior capsule of the lens in the left eye (c), and the vault in the right eye was $72 \mu \mathrm{m}(\mathbf{d})$ 


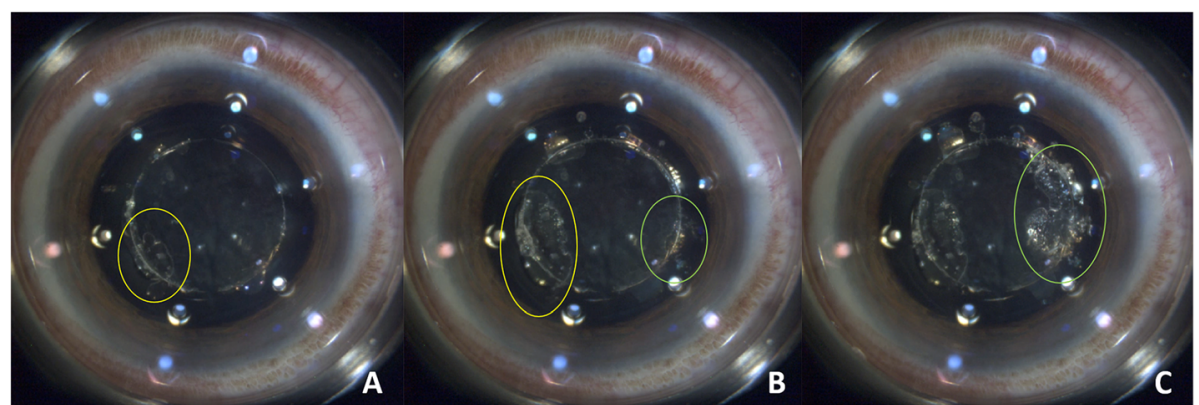

Fig. 2 The process of capsulotomy by femtosecond laser in the left eye (a to $\mathbf{c}$ ). The yellow circles indicate the big bubble's formation at two o'clock (from $\mathbf{a}$ to $\mathbf{b}$ ), while the green circles indicate the big bubble's formation at nine to 10 o'clock (from $\mathbf{b}$ to $\mathbf{c}$ )

formed (Fig. 4). The nuclear pre-fragmentation, however, failed again. Other steps of the surgery were the same as in the previous surgery and proceeded uneventfully. Both IOLs were well centered in the capsular bag at the end of the surgery.

However, it is worth noting that during the process of laser identification, the anterior ICL surface was accidently confused with the anterior capsule, not only in the shallow vaulted right eye, but also in the "0" vaulted left eye. Manual adjustment by the surgeon was needed to assign treatment zones to the anterior capsule surface in both eyes (Fig. 5).

The patient was instructed to apply topical dexamethasone tobramycin for 2 weeks and pranoprofen for 1 month postoperatively. At the two-week follow-up for the right eye (two-month follow-up for the left eye), in both eyes, the UDVA was 20/32, and the near uncorrected visual acuity (UCVA) was 20/25.

\section{Discussion and conclusions}

Cataracts are the most frequent complication after ICL implantation. The incidence of lens opacification has been reported in the literature as follows: $3 \%$ of eyes at 1 year [6], $4 \%$ to $11 \%$ at 2 years [7, 8], $7 \%$ to $13 \%$ at 5 years [9,10], $20 \%$ at 8 years [11], and $28 \%$ to $58.4 \%$ at 10 years $[12,13]$.
In our case, this patient received the ICL implantation 6 years ago, and developed cataracts almost 2 years ago. A shallow vault was found in both of his eyes. In the right eye, the vault was $72 \mu \mathrm{m}$. In the left eye, the AS-OCT showed the posterior surface of the ICL almost touching the anterior lens capsule, an existing " 0 " vault. The previous literature reported that the mean vault in eyes that developed cataracts was $103 \pm 69 \mu \mathrm{m}$ [14]. The vault in the left eye of our case was lower than the range which is reported.

Surgery is the only option for treating cataracts. The rates of phacoemulsification after ICL implantation are reported as $2 \%$ to $4.9 \%$ at 5 years $[9,13]$, and $17 \%$ to $18.7 \%$ at 10 years $[12,13]$. Our case had cataract surgery 6 years after ICL implantation. Compared with conventional phacoemulsification surgery, the FLACS is a safer and more precise surgery with advantages including more accurate capsulotomy, less corneal endothelial cell loss as well as better and faster visual rehabilitation $[1,2$, 15]. Parkhurst et al. and Li S. et al. indicated the efficacy and safety of FLACS in cataract patients with ICLs [4, 5]. However, more cases with different ICL vaults deserve further investigation. With the patient's strong will to undergo the FLACS, we chose the FLACS for him. Our case is reported as being the first in which the FLACS was performed on the "0" vault eye, and also the first case in which the surgery was performed on both eyes of one patient.

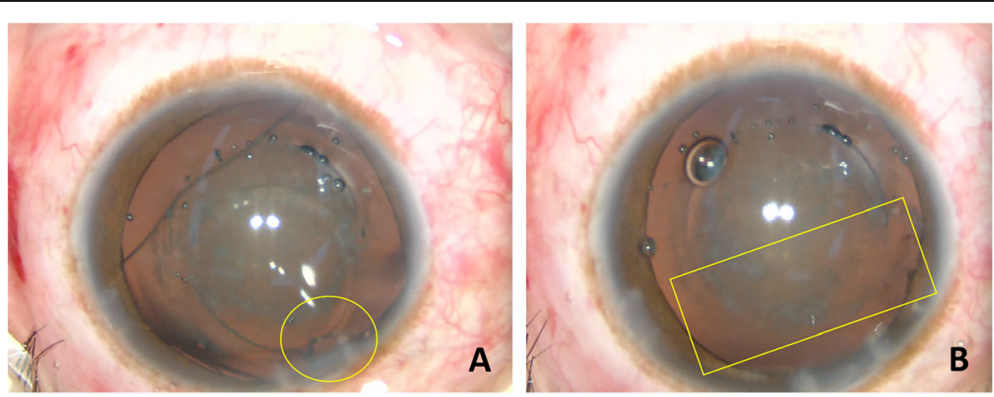

Fig. 3 The photographs of the left eye during the surgery (a to $\mathbf{b}$ ). a The yellow circle shows the rupture of the ICL. $\mathbf{b}$ The yellow rectangle shows the incomplete area of femtosecond laser assisted capsulotomy 


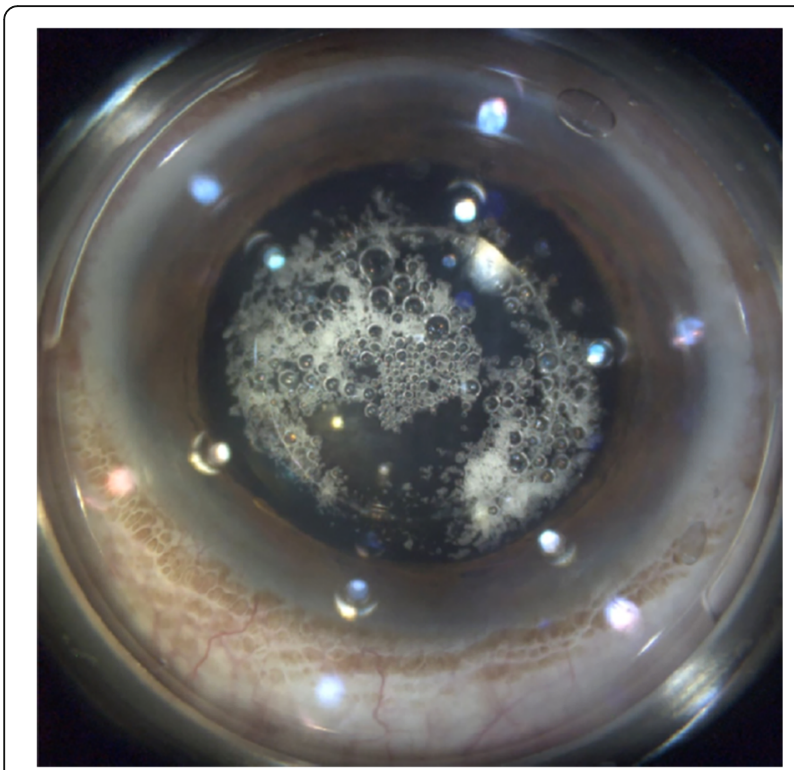

Fig. 4 The laser assisted capsulotomy in the right eye. Small cavitation bubbles smoothly dispersed to the central area

In the "0" vault left eye, we found that the cavitation bubbles were trapped in the shallow space between the ICL and the anterior lens capsule around the capsulotomy area, and that they could not disperse from the capsulotomy area to the center or the peripheral area. During the capsulotomy, small bubbles assembled to become big bubbles. These big bubbles have the potential to grind against the anterior capsule and lead to the position change of the capsule, which is the suggested cause of incomplete capsulotomy. In our case, a second capsulorhexis according to the laser tracks was safely made, which resulted in a well-centered IOL in the capsular bag. Comparatively, in the right eye, because of the remaining vault of $72 \mu \mathrm{m}$, the small cavitation bubbles smoothly dispersed to the center of the capsule, and no big bubbles formed; therefore, the complete capsulotomy was achieved. An incomplete capsulotomy was much harder to avoid in the " 0 " vault eye. We suggested that careful detection and an experienced second capsulorhexis were needed when facing the incomplete capsulotomy. In addition, similar to the shallowly vaulted eye which was reported by $\mathrm{Li}$ et al. [4], in our "0" vault eye, manual adjustment of the anterior capsule was also required to achieve laser manipulation correctly in the safe zone.

In our case, unsuccessful nuclear pre-fragmentation happened in both eyes. Parkhurst attributed the incomplete nuclear fragmentation to the frothy cavitation bubbles, which might have interfered with the subsequent laser delivery [5]. However, in the "0" vault eye, although there was no bubble beneath the ICL in the central area to interfere with the laser delivery, pre-fragmentation could not be tracked in the lens either. In our case, we suggested that the anterior subcapsular white opacity of the lens was the main cause of unsuccessful nuclear pre-fragmentation. The white opacity of the lens prevented the laser delivery; therefore, the laser could not make any meaningful cuts in the lens.

Previous literature suggested extracting the ICL through a temporal incision which is identical to the original one $[16,17]$. In the left eye of our case, in order to be consistent with regular phacoemulsification in Chinese surgical practices, we made the $2 \mathrm{~mm}$ superior incision; however, it was hard to extract the ICL directly. We needed to rotate the ICL to make its vertical angle face the incision, and then we pulled it hard. In the right eye of our case, we chose the $3 \mathrm{~mm}$ temporal incision and extracted the ICL directly. By comparison, we agreed with the previous reports, and suggested the temporal incision was more suitable for the ICL extraction.

Our report confirmed the feasibility of using a femtosecond laser in cataractous cases with shallowly vaulted ICLs. However, in the " 0 " vault eye, because there was little space for cavitation bubbles, the bubbles had the potential to press the anterior capsule downward and change its position. The surgeon should pay close attention to the incomplete laser capsulotomy. Manual adjustment was also required in the process of laser identification in the " 0 " vault eye.
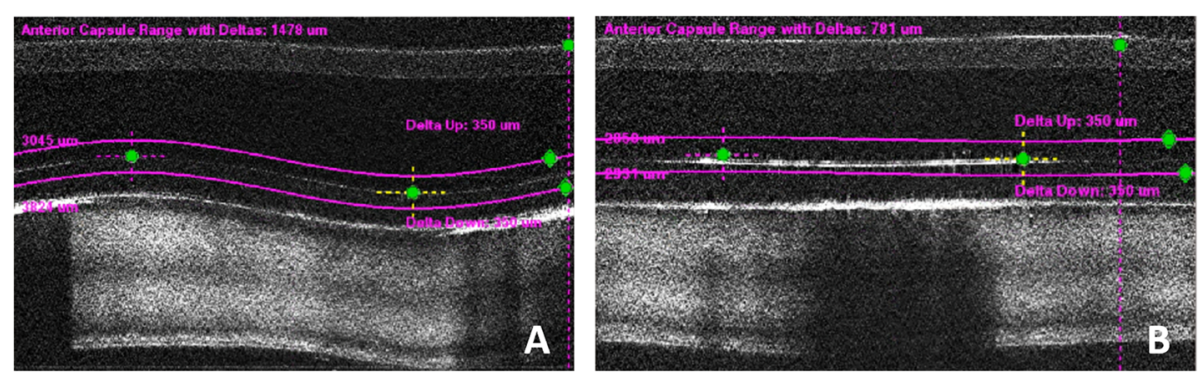

Fig. 5 Real-time OCT during FLACS (a to $\mathbf{b}$ ). The anterior ICL surfaces were identified as the anterior capsule in both eyes (a right eye; $\mathbf{b}$ left eye) 


\section{Abbreviations}

FLACS: Femtosecond laser assisted cataract surgery; ICLs: Implantable collamer lenses; IOL: Implantable ocular lens; UDVA: Uncorrected distance visual acuity; CDVA: Corrected distance visual acuity; UCVA: Uncorrected visual acuity; AS-OCT: Anterior segment optical coherence tomography; OVD: Ophthalmic viscosurgical device

\section{Acknowledgments}

Not applicable.

\section{Authors' contributions}

ZYN drafted the article and revised the manuscript. YYB did the surgery and drafted the article. ZCS collected date and drafted the article. All authors reviewed the manuscript. All authors read and approved the final manuscript.

\section{Funding}

This work was supported by the National Natural Science Foundation of China (Grant no.81470612, 81670832 and 81970779). The funding agency had no role in study design, data collection and analysis, or writing the manuscript.

\section{Availability of data and materials}

All data generated and analyzed during this study are included in this published article.

\section{Ethics approval and consent to participate}

This case report was approved by the ethics committee of the 2nd Affiliated Hospital, School of Medicine, Zhejiang University.

\section{Consent for publication}

Written informed consent was obtained from the patient for publication of this case report and any accompanying images.

\section{Competing interests}

The authors declare that they have no competing interests.

Received: 10 October 2019 Accepted: 14 April 2020

Published online: 05 May 2020

\section{References}

1. Zhu Y, Chen X, Chen P, Xu W, Shentu X, Yu Y, et al. Lens capsule-related complications of femtosecond laser-assisted capsulotomy versus manual capsulorhexis for white cataracts. J Cataract Refract Surg. 2019;45(3):337-42.

2. Chen $X, Y u$ Y, Song X, Zhu Y, Wang W, Yao K. Clinical outcomes of femtosecond laser-assisted cataract surgery versus conventional phacoemulsification surgery for hard nuclear cataracts. J Cataract Refract Surg. 2017:43(4):486-91.

3. Chee SP, Wong MH, Jap A. Management of severely subluxated cataracts using femtosecond laser-assisted cataract surgery. Am J Ophthalmol. 2017 173:7-15.

4. Li S, Chen X, Kang Y, Han N. Femtosecond laser-assisted cataract surgery in a Cataractous eye with implantable Collamer Lens in situ. J Refract Surg. 2016;32(4):270-2.

5. Kaur M, Sahu S, Sharma N, Titiyal JS. Femtosecond laser-assisted cataract surgery in Phakic intraocular Lens with cataract. J Refract Surg. 2016;32(2): $131-4$.

6. Sanders DR, Schneider D, Martin R, Brown D, Dulaney D, Vukich J, Slade S, Schallhorn S. Toric implantable Collamer Lens for moderate to high myopic astigmatism. Ophthalmology. 2007;114(1):54-61.

7. Kamiya K, Shimizu K, Igarashi A, Hikita F, Komatsu M. Four-year follow-up of posterior chamber phakic intraocular lens implantation for moderate to high myopia. Arch Ophthalmol. 2009;127(7):845-50.

8. Chung TY, Park SC, Lee MO, Ahn K, Chung ES. Changes in iridocorneal angle structure and trabecular pigmentation with STAAR implantable collamer lens during 2 years. J Refract Surg. 2009;25(3):251-8.

9. Sanders DR. Anterior subcapsular opacities and cataracts 5 years after surgery in the visian implantable collamer lens FDA trial. J Refract Surg. 2008;24(6):566-70

10. Lindland $\mathrm{A}$, Heger $\mathrm{H}$, Kugelberg M, Zetterstrom C. Vaulting of myopic and toric implantable Collamer lenses during accommodation measured with
Visante optical coherence tomography. Ophthalmology. 2010;117(6):124550.

11. Igarashi A, Shimizu K, Kamiya K. Eight-year follow-up of posterior chamber phakic intraocular lens implantation for moderate to high myopia. Am J Ophthalmol. 2014;157(3):532-9.

12. Schmidinger G, Lackner B, Pieh S, Skorpik C. Long-term changes in posterior chamber phakic intraocular collamer lens vaulting in myopic patients. Ophthalmology. 2010;117(8):1506-11.

13. Guber I, Mouvet V, Bergin C, Perritaz S, Othenin-Girard P, Majo F. Clinical outcomes and cataract formation rates in eyes 10 years after posterior Phakic Lens implantation for myopia. JAMA Ophthalmol. 2016;134(5):48794

14. Packer M. Meta-analysis and review: effectiveness, safety, and central port design of the intraocular collamer lens. Clin Ophthalmol. 2016;10:1059-77.

15. Chen $\mathrm{X}$, Chen $\mathrm{K}$, He J, Yao K. Comparing the curative effects between femtosecond laser-assisted cataract surgery and conventional phacoemulsification surgery: a meta-analysis. PLoS ONE. 2016;11(3): e0152088 Hejtmancik JF, editor.

16. Morales AJ, Zadok D, Tardio E, Anzoulatous G Jr, Litwak S, Mora R, Martinez E, Chayet AS. Outcome of simultaneous phakic implantable contact lens removal with cataract extraction and pseudophakic intraocular lens implantation. J Cataract Refract Surg. 2006;32(4):595-8.

17. Kamiya K, Shimizu K, Igarashi A, Aizawa D, Ikeda T. Clinical outcomes and patient satisfaction after Visian implantable Collamer Lens removal and phacoemulsification with intraocular lens implantation in eyes with induced cataract. Eye (Lond). 2010;24(2):304-9.

\section{Publisher's Note}

Springer Nature remains neutral with regard to jurisdictional claims in published maps and institutional affiliations.

Ready to submit your research? Choose BMC and benefit from:

- fast, convenient online submission

- thorough peer review by experienced researchers in your field

- rapid publication on acceptance

- support for research data, including large and complex data types

- gold Open Access which fosters wider collaboration and increased citations

- maximum visibility for your research: over $100 \mathrm{M}$ website views per year

At BMC, research is always in progress.

Learn more biomedcentral.com/submission 